\title{
Erratum to: Trends analysis of rhBMP utilization in single-level posterior lumbar fusion (PLF) in the United States
}

\author{
Lifeng Lao ${ }^{1} \cdot$ Jeremiah R. Cohen $^{2} \cdot$ Elizabeth L. Lord $^{2} \cdot$ Zorica Buser $^{3} \cdot$ \\ Jeffrey C. Wang ${ }^{3}$
}

Received: 4 June 2015/Revised: 4 June 2015/Accepted: 4 June 2015/Published online: 25 June 2015

(C) Springer-Verlag Berlin Heidelberg 2015

\section{Erratum to: Eur Spine J \\ DOI 10.1007/s00586-015-4032-9}

The authors want to add for Dr. Wang his general disclosures:

Financial activities outside the submitted work: Royalties-Stryker, Osprey, Biomet, Synthes, Seaspine, Amedica, Aesculap.

Investments/Options: Bon Biologics, Alphatech, Axiomed, Amedica, Corespine, Expanding Ortho, Pioneer, Axis, Syndicom, VG Innovations, Pearldiver, Flexuspine, Fziomed, Benvenue, Promethean, Nexgen, Electrocore, Surgitech.

Board of Directors: AO Spine, Collaborative Spine Research Foundation, North American Spine Society, Cervical Spine Research Society.

Fellowship Funding: AO Spine North America.

The online version of the original article can be found under doi:10.1007/s00586-015-4032-9.

Jeffrey C. Wang

jeffrey.wang@med.usc.edu

1 Department of Orthopaedic Surgery, Ren Ji Hospital, School of Medicine, Shanghai Jiao Tong University, Shanghai, China

2 Department of Orthopaedic Surgery, University of California at Los Angeles (UCLA), Los Angeles, CA, USA

3 Department of Orthopaedic Surgery, Keck School of Medicine of USC, 1520 San Pablo, HCT Suite 2000, Los Angeles, CA 90033, USA
Editorial Boards: Spine, JAAOS, The Spine Journal, Journal of Spinal Disorders and Techniques, Global Spine Journal, The Journal of Orthopaedic Trauma. 